Revista lus et Praxis, Año 24, № 1, 2018, pp. $101-128$

ISSN 0717 - 2877

Universidad de Talca - Facultad de Ciencias Jurídicas y Sociales

Presupuestos metodológicos de la teoría iusnaturalista de John Finnis

Carlos Isler Soto

Trabajo recibido el 13 de abril de 2016 y aprobado el 29 de noviembre de 2016

\title{
Presupuestos metodológicos de la teoría iusnaturalista de John Finnis*
}

\author{
Methodological PRESUPPOSITIONS OF JOHN FinNIS' \\ NATURAL LAW TheORY
}

\section{Carlos Isler Soto**}

\begin{abstract}
RESUMEN
La obra de John Finnis es, probablemente, la defensa más vigorosa de la teoría del derecho natural en filosofía jurídica contemporánea. Su filosofía jurídica comienza con una reflexión metodológica relativa al modo de formar conceptos por el teórico general del derecho, que debe mucho a la tradición clásica y a autores contemporáneos como Hart. En este trabajo exponemos de modo sistemático, y a partir de todas sus obras relevantes, la metodología defendida por Finnis y la justificación que hace de la misma, metodología que se encuentra en la base de su pretensión de que el concepto del derecho en su caso central debe ser uno moralmente cargado. Se analiza el modo como utiliza el método hermenéutico, la analogía, y el consiguiente recurso a conceptos como caso central o punto de vista interno. Se concluye con unas breves reflexiones sobre los supuestos en filosofía moral de su obra jurídica.
\end{abstract}

\section{Palabras clave}

John Finnis - iusnaturalismo - ley natural - metodología en teoría del derecho.

\section{ABSTRACT}

John Finnis' work is, probably, the most sound defense of Natural Law Theory in Contemporary Legal Philosophy. His Legal Philosophy begins with a methodological reflection concerning the formation of concepts by general legal theorists that is highly indebted to the Classical tradition and to contemporary authors such as Hart. In this work, we expose systematically, and recurring to all his relevant works, the methodology defended by Finnis and its justification, methodology

\footnotetext{
* Este artículo se enmarca en un proyecto de investigación más amplio relativo a la fundamentación de la tesis de la conexión necesaria entre derecho y moral verdadera en el iusnaturalismo contemporáneo en la obra de John Finnis, Mark Murphy y Michae Moore, el desarrollo del cual ha sido posible gracias a una Beca Postdoctoral del Gobierno Mexicano que me ha permitido realizar una muy provechosa pasantía de investigación en el Instituto de Investigaciones Jurídicas de la UNAM. Agradezco los comentarios de los profesores Javier Saldaña Serrano y Rodolfo Luis Vigo, que me fueron de mucho provecho.

** Licenciado en Ciencias Jurídicas y Sociales, Universidad Austral de Chile. Abogado. Licenciado en Filosofía, Universidad de los Andes. Doctor en Derecho, Pontificia Universidad Católica de Chile. Profesor de Filosofía del Derecho, Universidad Bernardo O`Higgins, Chile, y de Introducción al Derecho, Universidad Mayor, Chile.

Correo electrónico: carlos_isler@yahoo.com
} 
that grounds his claim that the concept of law in its central case is a morally charged one. We analyse the way he uses the hermeneutic method, analogy, and the consequent resort to concepts like central case or internal point of view. We conclude with some brief remarks on the moral philosophical presuppositions of his legal work.

\section{Key Words}

John Finnis - Natural Law Theory - Natural Law - Methodology in Legal Theory.

\section{Introducción}

John Finnis es, probablemente, el autor iusnaturalista en filosofía del derecho más importante del siglo XXI. El término "iusnaturalista", sin duda, puede significar variadas cosas. Michael Moore, por ejemplo, en un artículo en el que defiende la tesis iusnaturalista en filosofía del derecho, hace un catálogo de otros usos de "ley natural" distintos de los que él mismo defiende, referidos sobre todo a temas de filosofía moral. Así, para Michael Moore, un autor es iusnaturalista en filosofía jurídica si defiende dos tesis: "(1) hay verdades morales objetivas; y (2) la verdad de cualquier proposición jurídica necesariamente depende, al menos en parte, de la verdad de alguna proposición moral correspondiente ${ }^{\prime 1}$. Precisamente tal es lo que defiende John Finnis: que sólo se puede hacer una teoría general del derecho a partir de la consideración de lo que sea realmente bueno para el hombre, aquello que posibilite su florecimiento, o, si se quiere, que existe una conexión necesaria entre el derecho y la moral verdadera.

En otras palabras, la tesis iusnaturalista en materia de filosofía jurídica consistiría en la negación de la conocida tesis positivista de que no hay conexión necesaria entre el derecho y la mora y, además, en la afirmación de que dicha conexión se da entre el derecho y la moral verdadera². La tesis positivista se

\footnotetext{
1 Moore (1992), p. 189. Los otros usos que identifica de "teoría de la ley natural" se refieren al realismo moral mismo; a una particular especie de realismo moral: el naturalismo metaético (como opuesto al no naturalismo metaético); a un tipo particular de este realismo moral naturalista: aquel que identifica las propiedades normativas con propiedades de la naturaleza humana; y a la escuela que en metaética se Ilama "Teoría del Mandato Divino". Es claro que, cuando muchos se refieren en el debate contemporáneo a la "ley natural", sea para explicitar sus exigencias o para negar su existencia, se refieren a la "ley moral", entendida como teniendo realidad objetiva. También en Finnis hay una teoría de la ley natural en este sentido, vale decir, una teoría de la ley moral, pero no será objeto del presente estudio.
}

2 Porque puede haber quienes afirmen la existencia de una conexión necesaria entre derecho y moral positiva, o entre derecho y moral, pero concebida ésta como irracional o subjetiva. Por eso, la tesis iusnaturalista en filosofía del derecho no es sólo la negación de la tesis de la conexión entre derecho y moral, como tradicionalmente se la enuncia. Philipp Soper, por ejemplo, la enuncia así: "When the phrase 'natural law' is used in jurisprudence it almost always refers to the claim, in opposition to positivism, that there is a necessary connection between law and morals": Soper (1983), p. 1180; y luego expresa que "...even the moral relativist or emotivist say, who claims that value statements are just personal expressions of approval or disapproval could still be a natural law legal theorist. He 
impuso durante buena parte del siglo XX, sobre todo por la vigorosa defensa que de la misma hicieron autores como H.L.A. Hart. Para Hart, una teoría general y descriptiva del derecho debe partir por reconocer que no hay conexión necesaria entre derecho y moral. Sostener lo contrario llevaría a resultados claramente contraintuitivos, como que en países enteros no hay sistema jurídico, o que leyes que en ciertos países son injustas pero surgieron de los órganos legislativos normales, son aplicadas por los tribunales y son Ilamadas "leyes" (como las leyes racistas de Nüremberg) no son en realidad leyes -de modo que el conjunto completo de los funcionarios públicos de un país estaría equivocado respecto de cuál sea el derecho vigente en tal país ${ }^{3}$-, o que no entendamos qué signifique "derecho" en su uso común sin entender que sea algo moralmente valioso. Tales serían las consecuencias absurdas de adoptar la tesis contraria, que podría resumirse en el conocido dicho agustiniano "la ley injusta no es ley". Tal cosa, decía ya Austin, podrá ser correcta si se refiere a cómo debería ser el derecho o la ley, pero claramente no lo es si se refiere al derecho tal como es o puede ser ${ }^{4}$.

El positivismo así entendido, como la simple negación de que exista conexión necesaria entre derecho y moral, o como la negación de que la justicia sea condición necesaria de juridicidad de una supuesta ley, no implica negar la posibilidad de la existencia de una moral objetiva a partir de la cual se pueda juzgar críticamente el derecho positivo y, eventualmente, se decida desobedecerlo ${ }^{5}$. No implica -ni excluye- posición alguna respecto de la naturaleza de la moralidad, o la existencia o inexistencia de una obligación moral absoluta o limitada de obedecer al derecho positivo. De ahí que sea tan atractivo el positivismo así entendido para muchos: afirma la posibilidad de hacer teoría descriptiva y general del derecho sin necesidad de entrar en discusiones ni tomar posición -al menos qua filósofos del derecho- sobre temas tan controvertidos como la naturaleza de la moral y las obligaciones morales, o sus exigencias.

Frente a dicha tesis, diversos autores contemporáneos han levantado poderosas objeciones. Muy conocida es la crítica al positivismo hartiano realizada por Lon Fuller -afirmando frente a Hart la existencia de una moral intrínseca

could, that is, insist that we identify systems as 'legal' if and only if certain people expresses approval of the basic rules of the system. Like some natural lawyers, he could then say that directives that are very evil are not law, though by 'evil' he just means intensely disapproved by the relevant group, not evil 'in fact'": SOPER (1983), p. 1181.

3 Así, por ejemplo, Andrei Marmor: "at some point one would have to doubt whether a theory that renders a great part of the law to be a legal error is really a theory that tells us what the law is": Marmor (2011), p. 91.

4 Austin (1998), p. 184.

5 HART (1958). 
al derecho, el Imperio del Derecho- ${ }^{6}$, o la defensa de Alexy de la conexión necesaria entre derecho y moral por medio de la defensa de la tesis de la pretensión de corrección de cada norma jurídica ${ }^{7}$. Más recientemente, autores como Mark Murphy -apoyándose en Alexy- ${ }^{8}$ o Michael Moore ${ }^{9}$ han desarrollado sofisticadas defensas de la tesis iusnaturalista en filosofía del derecho. Pero, claramente, ha sido la defensa que de la misma ha realizado John Finnis la que mayor repercusión ha tenido, al punto de que varios autores autodenominados "positivistas" han aceptado el modo de argumentar de Finnis y han defendido la necesidad de reformular la tesis positivista de modo que sea compatible con la aceptación de la crítica finnisiana a su versión original, dando origen al llamado "positivismo normativo".

En el presente trabajo, queremos exponer cuál es la crítica de Finnis a la tesis positivista entendida al modo de Hart. Para ello, será necesario exponer las consideraciones de Finnis relativas a las exigencias metodológicas de una teoría general y descriptiva del derecho, ya que son tales exigencias metodológicas las que determinan la crítica que realiza a la tesis positivista.

Nos parece que el presente trabajo viene a llenar un vacío en la bibliografía sobre la Ilamada "Nueva Teoría de la Ley Natural" en general, y sobre la obra de Finnis, en particular. En efecto, se ha escrito profusamente sobre la teoría moral de Finnis, y ha llamado la atención especialmente de los estudiosos su afirmación de la existencia de bienes humanos básicos, el carácter premoral de éstos, o el carácter no derivado del primer principio de la razón práctica respecto de principio teórico alguno. Sin embargo, la doctrina esencial de la filosofía jurídica de Finnis, su argumentada defensa de la superioridad metodológica de una teoría iusnaturalista respecto de una teoría positivista del derecho ha sido, curiosamente, objeto de poco estudio, y no ha sido objeto de un tratamiento sistemático a partir de sus numerosas obras ${ }^{10}$. Muchas veces ha sido pasada por

6 FULLeR (1969).

7 AleXY (2011).

8 Murphy (2006) y (2007).

9 Moore (1992). Moore es claramente un iusnaturalista en materia de filosofía del derecho, en cuanto sostiene la existencia de una moral objetiva y una conexión necesaria entre el derecho y ésta. Sin embargo, se diferencia bastante de los autores de la tradición iusnaturalista clásica en cuanto no es teísta y, por ende, Dios no juega papel alguno en su teoría moral -véase MOore (1996)-, y sus posiciones morales sustantivas difieren bastante de las defendidas comúnmente por los autores de la tradición. Por ejemplo, defiende la licitud del aborto y de la tortura no sólo a terroristas, sino también a familiares de éstos cuando posean información relevante para salvaguardar bienes mayores -por ejemplo, en el llamado "escenario de la bomba de tiempo"-, véase MOORE (1989).

10 Resulta curioso el capítulo I de "Ley Natural y Derechos Naturales", que para un filósofo del derecho es claramente el más importante, haya sido objeto de tan poco comentario. En castellano, dentro de la 
alto por ciertos críticos, que la han entendido mal. Curiosamente, son ciertos autores positivistas, como Jeremy Waldron y Neil McCormick, quienes mejor la han entendido, hasta el punto de que se ven obligados a reformular la tradición positivista de modo que sea compatible con la aceptación de la crítica finnisiana a la metodología del Ilamado "positivismo conceptual".

\section{La elección del caso central y la clarificación de la respuesta iusnaturalista a la pregunta por la ley injusta}

Ante todo, se debe ver cómo Finnis explica la posición iusnaturalista respecto del carácter jurídico de las leyes injustas. Y es que, precisamente, una mala comprensión del dictum agustiniano ha llevado a una incomprensión y hasta caricatura de las pretensiones de una teoría iusnaturalista como teoría general del derecho. Cuando San Agustín y Santo Tomás de Aquino niegan juridicidad a la ley injusta, se están refiriendo al caso central de ley.

Finnis retoma la exigencia metodológica defendida por Hart respecto de la necesidad de describir del modo más rico posible un caso central de la realidad estudiada, caso central por referencia al cual pueden ser llamadas del mismo modo y estudiadas las realidades que se les asemejen, pero que no posean todas las características del caso central. Hart rompe así con la pretensión de los positivistas anteriores a él de que se debía describir un concepto de derecho mediante la enumeración de un conjunto de propiedades, cuya posesión conjunta por un ítem fuese condición necesaria y suficiente para Ilamarlo "derecho"11. Y es que tal pretensión podía llevar a resultados tan absurdos como negarle todo carácter jurídico a realidades como el derecho internacional o el derecho canónico, por no poseer todas aquellas propiedades, que son las que posee el derecho estatal. Tal pretensión es tan poco sensata como querer describir lo que sea el fútbol y luego negarle carácter futbolístico a juegos que no compartan absolutamente

numerosa bibliografía dedicada a la obra de Finnis, tratan sobre el tema sólo GarCía-HuidOBRO (1991), Legarre (1999), Hocevar (2006) y Pereira Sáez (2006) y (2008), pp. 4-39. Incluso, si se aprecia la excelente colección de artículos en ETCHEVERRY 2013, dedicada especialmente a la segunda edición de Natural Law and Natural Rights, no hay contribución alguna que trate sobre el tema.

En la bibliografía anglosajona, aunque no hay un tratamiento sistemático y completo de la teoría metodológica de Finnis, ésta sí ha sido muy discutida, atacada y defendida, a propósito, precisamente, de la disputa sobre la relación necesaria o no entre derecho y moral. Por ejemplo, véase Bıx (1999) y (2005), WALDRON (2000) y (2001), MCCORMICK (1992), EHRENBERG (2009) y las diversas contribuciones a KeOwn y George (2013) que discuten el tema: Simmonds (2013), ENDicott (2013) - quien expresa que "The exposition of Method, in Chapter 1 of Natural Law and Natural Rights, was a landmark in analytical jurisprudence" (2013), p. 327, Dickson (2013), Köpcke Tinturé (2013), y las consiguientes respuestas de Finnis en, FinNIS (2013).

11 Hart defiende esta exigencia metodológica por influencia de Wittgenstein. Aunque Finnis la acepta, él la recibe de Aristóteles y sus usos de la analogía para describir realidades como la amistad. 
todas las características enunciadas en la descripción. Ello llevaría al resultado absurdo de negarle carácter futbolístico a claras instancias del juego fútbol, y que incluso llamamos preteoréticamente como "fútbol", por ejemplo, el típico partido de estudiantes en el cual juegan por cada equipo números distintos de jugadores de los requeridos en un caso central (por ejemplo, un partido de escolares en el cual nueve de ellos juegan contra once). No sólo llamamos "fútbol" a tal juego, sino que además sus mismos participantes guían sus acciones guiándose y tomando como modelo aquellas que realizan quienes juegan en el caso central, se guían por las mismas reglas que rigen este caso, salvo una que otra modificación menor.

Es sabido que para Hart el derecho en su caso central es "la unión de reglas primarias y secundarias", y las realidades que se le asemejen pueden ser Ilamadas "derecho" por analogía, por tener "un aire de familia", con el caso central, y estudiadas como casos no centrales de derecho. El concepto que dará Finnis de derecho, según se verá, es mucho más exigente y complejo que el dado por Hart, de modo que habrá ítems que calificarían como instancias del caso central en Hart, pero no en Finnis. Pero, nuevamente, ello no llevará al filósofo australiano a negar carácter jurídico a tales ítems ${ }^{12}$. Más bien, se trata de ítems con juridicidad disminuida, vale decir, genuinas instancias de sistema jurídico o de ley, pero deficientes en cuanto tales, no sólo moralmente deficientes -lo que un positivista podría conceder-, sino que también jurídicamente deficientes. Lo que el iusnaturalista pretende al incluir la satisfacción de ciertos criterios de moralidad verdadera como criterios de juridicidad de un ítem ${ }^{13}$, no es negar todo carácter jurídico ni negar que puedan ser genuinas instancias de sistema jurídico o ley, o lo que sea, aquellos ítems que no satisfagan tal o cual criterio de moralidad, sino que tales ítems son, y por consiguiente, deben ser estudiados como casos desviados o defectuosos. Del mismo modo, quien incluye en el concepto de perro el que éste tenga cuatro patas, no pretende negar carácter perruno, o negar que sea un perro, aquel animal que satisfaga todos los otros requisitos para calificar como perro, pero que nazca con tres patas. Un perro con tres patas es, claramente, un perro, pero es un perro deficiente como perro (y, dado que aquí no se trata de una deficiencia moral sino física, precisamente ese carácter deficiente justifica que lo tratemos de un modo distinto y más cariñoso que como tratamos a los otros perros), y lo estudiamos como un perro

12 Como han pretendido hacer afirmar a los teóricos iusnaturalistas aquellos positivistas que han reducido la tesis iusnaturalista en materia de filosofía del derecho a la afirmación del eslogan "la ley injusta no es ley", eslogan, además, que han malinterpretado. Véase, al respecto, RusseLl (2000).

13 Como lo hace Finnis en su definición de derecho -véase más abajo-, o Santo Tomás en su conocida definición de ley: "rationis ordinatio ad bonum commune, ab eo qui curam communitatis habet, promulgata" (Summa Theologiae I-II, q. 90. a. 4 resp). 
con defectos en cuanto perro. Ningún veterinario, al explicar la anatomía del perro a sus estudiantes, tomaría como modelo a aquel perro que nació con tres patas. Tiene bien claro que el concepto de perro incluye el tener cuatro patas. Y también tiene bien claro que si le llevan a uno con tres patas, no dirá "¿qué animal es éste?". De ahí que la pretensión positivista de que el iusnaturalista en materia de filosofía del derecho debe comprometerse con la aceptación de consecuencias tan descriptivamente contraintuitivas como que en la Alemania nazi o en la Cuba de Castro realmente no había derecho, sea simplemente absurda. Había derecho, deficiente como derecho, y es ese carácter deficiente el que justifica, por lo demás, que no reciba por parte de sus súbditos el mismo trato que puede exigir un caso central de derecho. Así, por ejemplo, "existen casos centrales de gobierno constitucional, y hay casos periféricos (como la Alemania de Hitler, la Rusia de Stalin, o incluso la Uganda de Amin). Por un lado, no tiene sentido negar que los casos periféricos son instancias (de amistad, constitucionalidad...). De hecho, el estudio de ellos es iluminado al pensarlos como versiones debilitadas de los casos centrales o, en ocasiones, como explotaciones de actitudes formadas por referencia al caso central"14.

Ahora bien, la distinción entre caso central y casos periféricos puede permitir a Finnis eludir las paradojas o los resultados descriptivamente contraintuitivos asociados por los positivistas tradicionales a la inclusión de criterios de corrección moral en la definición de derecho ${ }^{15}$. En otras palabras, Finnis ha mostrado la posibilidad de elaborar una teoría general del derecho iusnaturalista sin caer en los problemas mencionados. Sin embargo, Finnis pretende no sólo que es posible una teoría iusnaturalista del derecho, sino que, además, si se trata de elaborar una teoría general del derecho, entonces es necesario que ésta sea iusnaturalista. Veremos cómo argumenta en tal sentido.

\section{Una teoría del derecho y no del "concepto" de derecho}

Un segundo aspecto importante a destacar es que Finnis declara expresamente que pretende elaborar un concepto de derecho, pero que su teoría trata sobre el derecho, no sobre el concepto supuestamente común vehiculado por

14 FinNIS (1980), p. 11.

15 Lo que reconocen autores contemporáneos de la tradición positivista: cfr., "...in fact modern natural law theorists are quite cautious about the application of 'lex iniusta non est lex', and quite sophisticated in their treatment of the implied paradox 'lex...non est lex"": WaLdRON (2001), p. 416; "He [Finnis] offers several elaborate (and convincing) explanations of why this paradox is not a contradiction. His explanations appeal to the distinction between normative, descriptive, and detached uses of terms like 'law', as well as to the further distinction, central to his jurisprudence, between the focal meaning and the secondary meaning of such terms": WALDRON (2001), p. 416. 
el término "derecho" cuando éste es usado en el habla cotidiana o en el habla de los juristas.

Se sabe que durante la primera mitad del siglo XX, fue una moda en el ámbito anglosajón el reducir todos los problemas filosóficos al análisis del lenguaje de los términos usados en la expresión de dichos problemas ${ }^{16}$. Así, una serie de filósofos del derecho, siguiendo la moda filosófica general, cuando desarrollaban su teoría general del derecho afirmaron estar simplemente analizando el significado de "derecho", sea cuando este término es usado en el habla cotidiana, sea cuando es usado por los juristas. Seguramente, pretender hablar de la realidad misma, aunque sea una realidad social, les parecía demasiado ambicioso.

Finnis es bien claro respecto de que no pretende realizar análisis lingüístico alguno, y es que tal empresa es simplemente poco interesante y no cae bajo el ámbito de estudio de la filosofía del derecho, la que pretende realizar una teoría general del mismo: "el análisis conceptual y las apelaciones a la intuición no pueden dar nada más que 'resultados etnográficamente relativos', una lexicografía o 'lexicografía glorificada' o 'lexicografía pop' cuyos resultados son 'estrictamente etnográficos y locales', una 'sociología descriptiva banal del tipo encuesta Gallup"'17.

Así, no resulta decisivo para apreciar el valor de un concepto de derecho propuesto por un teórico, el que este se corresponda exactamente con el concepto vehiculado por el término "derecho" en cualquiera de sus usos. Tampoco puede considerarse que el término "derecho" en cualquiera de sus usos fije de forma definitiva el referente de la realidad estudiada. Es, precisamente, lo que Finnis critica a Kelsen, cuando éste expresa que se debe hacer tal ${ }^{18}$.

16 Finnis es particularmente claro respecto a que no pretende realizar análisis lingüístico: su definición de derecho "is not advanced with the intention of 'explaining correctly our [sc. the ordinary man's] ordinary concept of law'. For the truth is that the 'ordinary concept of law' (granting, but not admitting, that there is one such concept) is quite unfocused. It is a concept which allows 'us' to understand lawyers when they talk about sophisticated legal systems, and anthropologists when they talk about elementary legal systems, and tyrants and bandits when they talk about the orders and the customs of their Syndicate, and theologians and moralists... There is no point in trying to explain a commonsense concept which takes its meanings from its varied contexts and is well understood by everyone in these contexts. My purpose has not been to explain an unfocused 'ordinary concept' but to develop a concept for use in a theoretical explanation of a set of human actions, dispositions, interrelationships, and conceptions...": FinNIS (1980), p. 278.

17 Finnis (2011a), p. 35 (las frases entre comillas simples son citas que hace Finnis de un texto de Brian Leiter).

18 KeLSEN (2007), p. 19: "What could the so called-law of Ancient Babylonians have in common with the law that prevails today in the United States? What could the social order of a negro tribe under the leadership of a despotic chieftain -an order likewise called 'law'- have in common with the constitution of the Swiss Republic? Yet there is a common element that fully justifies this terminology, and enables the word 'law' to appear as the expression of a concept wth a socially highly significant meaning. For 
Lo pretendido por Kelsen es tan absurdo como pretender fijar de modo definitivo el objeto de una teoría general del fútbol analizando el referente que en una determinada comunidad lingüística tiene el término "fútbol" y, en consecuencia, dejar fuera de tal objeto de estudio, incluso como un posible caso periférico, a un partido de 9 contra 10 jugadores, sin árbitro, sólo porque éste es Ilamado mayoritariamente en tal comunidad lingüística -y sólo en tal comunidad- "pichanga", no obstante las enormes similitudes entre la "pichanga" y la final de la Copa América de Fútbol, similitudes que incluyen el hecho no menor de que los participantes en la "pichanga" modelan sus actitudes y se rigen por las mismas reglas -salvo la relativa al número de jugadores- que aquellas por las cuales se rigieron quienes jugaron la mencionada final.

\section{El carácter derivado de una teoría descriptiva respecto de una teoría normativa. La necesidad de la asunción del punto de vista interno}

Cuando se pregunta qué tipo de teoría general es la que pretende desarrollar Finnis en Natural Law and Natural Rights, declara expresamente que es una teoría normativa ${ }^{19}$. Sin embargo, para Finnis toda teoría descriptiva es siempre derivada de alguna teoría general normativa ${ }^{20}$. Finnis se opone al lugar común positivista según el cual primero se debería realizar una teoría general descriptiva, la cual sería moralmente neutral, y luego, ello posibilitaría el desarrollo de una teoría normativa.

Para Finnis, la situación es precisamente la contraria: toda teoría general del derecho es inicialmente normativa, y llegamos a tal conclusión si se analiza cuál es el método correcto para desarrollar los conceptos que se habrán de utilizar en tal teoría general.

Así, para el filósofo australiano, los primeros teóricos positivistas anglosajones, Austin y Bentham, no fueron conscientes del problema de la justificación de la elección de los conceptos utilizados en una teoría general del derecho. Simplemente inician su teoría del derecho poniendo una serie de definiciones, con la confianza de que la experiencia luego se habrá de ajustar a lo prescrito

\footnotetext{
the word refers to that specific social technique of a coercive order which, despite the vast differences existing between the law of Ancient Babylon and that of the United States of today, between the law of the Ashantis in West Africa and tht of the Swiss in Europe, is yet essentially the same for all these peoples...".

19 FINNIS (2011j), p. 418: "The book's programme and explanations are justificatory...".

20 FINNIS (2011j), p. 418: "...descriptive social theory is a legitimate project but dependent, for the critical formation of its own concepts, on fully normative considerations..."; FINNIS (2011g), p. 255: "descriptive social theory will be unable to get beyond an endless video of local histories -or a merely statistical ordering of them- unless it makes the judgments about reasonableness that are fundamental to practical social theory".
} 
por aquellas definiciones, una confianza claramente infundada si se considera cuántos fenómenos jurídicos, por ejemplo, la costumbre, se muestran refractarios a ser descritos por una teoría como la de Austin.

Teóricos posteriores, como Hart y Raz, mostraron tener una mayor conciencia del problema. "Una ciencia social, tal como la teoría del derecho analítica o sociológica, intenta describir, analizar y explicar algún objeto o materia. Este objeto está constituido por acciones, prácticas, hábitos, disposiciones humanas, y por el discurso humano. Las acciones, prácticas, etcétera, son ciertamente influenciadas por las causas 'naturales' investigadas propiamente con los métodos de las ciencias naturales, incluyendo una parte de la ciencia de la psicología. Pero las acciones, prácticas, etcétera, pueden ser comprendidas completamente sólo comprendiendo su razón de ser (their point), es decir, su objetivo, su valor, su significación o importancia, tal como son concebidos por las personas que las realizan, se involucran en ellas, etcétera"21.

Concebir el fin de la práctica tal como lo hacen sus participantes, es lo que Hart Ilamaba asumir el "punto de vista interno". Este principio metodológico exige, según Hart, comenzar la descripción de una realidad social haciéndolo tal como lo harían quienes participan en y, con sus prácticas constituyen a, dicha práctica social, aun cuando en definitiva el teórico social no comparta personalmente tal punto de vista ${ }^{22}$. Se oponía, con ello, especialmente a la pretensión de los realistas jurídicos estadounidenses que sostenían que para captar la verdadera esencia del derecho se debía asumir la perspectiva del hombre malo. Así decía el protorrealista Oliver Wendell Holmes que "si quieren conocer el derecho y nada más, deben verlo como un hombre malo, que se preocupa sólo por las consecuencias materiales que tal conocimiento le permite predecir, no como un hombre bueno que encuentra las razones para su conducta, sea dentro del derecho o fuera de él, en las más vagas sanciones de su conciencia" ${ }^{23}$. De modo poco sorprendente, asumida imaginativamente

\footnotetext{
21 FINNIS (1980), p. 3.

22 Es lo que algunos han Ilamado "metodología hermenéutica". Véase Leiter (2009), p. 254, n. 3: "the internal point of view'... grow out of the hermeneutic tradition in the philosophy of social science. According to this tradition, the only way to understand human practices is by understanding their meaning to participants in those practices". También Bıx (2009), p. 41.

Hart también llamó a su empresa "hermenéutica": "what is needed is a 'hermeneutic' method which involves portraying rule-governed behavior as it appears to its participants, who see it as conforming or failing to conform to certain shared standards": HART (1983), p. 13.

23 HOLmes (1897), p. 459.

Los realistas posteriores herederán tal actitud. Véaseel elogio de la misma en Frank (2009), pp. 134135. Si bien es cierto que, en otras ocasiones, Frank parece asumir la perspectiva del abogado litigante al momento de describir el derecho, es claro que se trata del abogado litigante que está dispuesto a ponerse al servicio de "nuestro amigo el hombre malo".
} 
tal situación por el teórico descriptivo, el derecho pasaba a ser "las profecías de lo que los tribunales harán de hecho"24.

Para Hart, dicha tesis es insostenible, desde que la idea misma de actividad judicial supone la existencia de reglas constitutivas del rol del juez, y de reglas que éste debe aplicar ${ }^{25}$. Asumida, en cambio, la perspectiva de quienes con sus prácticas crean y dan forma a la realidad jurídica, vale decir, lo que llama el "punto de vista interno" 26 , el derecho se nos aparece, dice Hart como un conjunto de reglas sociales de dos tipos: las primarias, que establecen obligaciones, y las secundarias, que se refieren a las primeras y confieren potestades públicas o privadas. Y la noción de regla, afirma Hart, supone la de aceptación: cuando una regla es usada por una serie de personas, esta serie de personas tiene que, necesariamente, haber aceptado que el comportamiento prescrito por la regla es un comportamiento que debe ser seguido por el grupo como un todo. Ello diferencia a una regla de un mero hábito, y ello también explica que este conjunto de personas critique a aquella otra persona del grupo cuyo comportamiento se desvíe respecto del prescrito por la regla.

Pero aceptar una regla no significa necesariamente según Hart, aceptarla por razones morales. Se puede aceptar, tanto una regla específica como un sistema normativo entero, además de por razones morales, por razones de otro tipo, como una actitud irreflexiva heredada o tradicional, el mero deseo de hacer como los demás, interés desinteresado por los demás o cálculos de interés a

24 Holmes (1897), p. 461. El párrafo completo muestra la conexión entre la definición de derecho y el punto de vista asumido: "But if we take the view of our friend the bad man we shall find that he does not care two straws for the axioms or deductions, but that he does want to know what the Massachusetts or English courts are likely to do in fact. I am much of his mind. The prophecies of what the courts will do in fact, and nothing more pretentious, are what I mean by law".

También, Holmes (1918), p. 42: "But for legal purposes a right is only the hypostasis of a prophecy -the imagination of a substance supporting the fact that the public force will be brought to bear upon those who do things said to contravene it- just as we talk of the force of gravitation accounting for the conduct of bodies in space".

25 Hay interpretaciones contemporáneas según las cuales Hart y otros habrían malinterpretado a los realistas, ya que éstos en realidad no habrían pretendido desarrollar una teoría general del derecho orientada a esclarecer la naturaleza del derecho, sino más bien una teoría orientada a determinar cómo predecir de mejor modo las decisiones de los jueces. Así, Andrei Marmor: "To put the matter simply, the realists were not interested in the philosophy of law. They just wanted to set a new research agenda, an agenda that focuses on the kinds of tools we need to be able to determine how judges reach their decisions, and what would enable us to predict the kinds of decisions they are likely to make in the future": MARMOR (2011), p. 32. En todo caso, el modo como Hart entendió a los realistas es el modo como han sido entendidos en general hasta hace muy poco, particularmente hasta la aparición de la reinterpretación de los mismos que hace Brian Leiter. Cfr. LeITER (1999) y (2001).

26 HART (1994a), pp. 90 y 242. 
largo plazo ${ }^{27}$. De ahí que, para Hart, el teórico descriptivo del derecho no deba necesariamente realizar su tarea descriptiva asumiendo la perspectiva de quien cree que hay razones morales para que exista el derecho. Más aún, como el teórico descriptivo sólo ha de asumir la perspectiva de quien acepta las reglas que constituyen el sistema jurídico -sean cuales fueren las razones por las cuales esta persona acepta dichas reglas-, pero no está obligado a compartir personalmente la aceptación o las valoraciones en las que se basa la aceptación de la regla o el sistema por parte de aquella persona cuyo punto de vista asume, entonces, cree Hart la empresa descriptiva puede ser valorativamente neutral. Y precisamente por eso, es meramente descriptiva. Una teoría normativa del derecho será posterior, y supone una previa descripción del objeto que se quiere valorar.

Ahora bien: John Finnis acepta la exigencia metodológica hartiana de asumir el punto de vista interno ${ }^{28}$, pero va a rechazar las otras dos exigencias metodológicas que Hart asociaba a dicha asunción: que se deba asumir la perspectiva de quien acepta el sistema jurídico, cualesquiera que sean las razones por las cuales lo acepta, y, que el teórico pueda pretender distanciarse de aquella posición, de modo de realizar una descripción valorativamente neutral. Veremos ello a continuación.

\section{Las exigencias de la asunción del punto de vista interno según Finnis. La necesidad de asumir el punto de vista del hombre prácticamente razonable}

Comenzaremos por el segundo tema anteriormente mencionado: ciertamente se puede realizar la descripción de una realidad social asumiendo, sin compartir, el punto de vista de tal o cual persona que participe en dicha realidad ${ }^{29}$, pero ello dará como resultado cualquier cosa menos una teoría general de aquella

\footnotetext{
27 HART (1994a), pp. 197 y 203.

28 Lo que se encuentra exigido, además, por la adopción de la metodología del caso central y casos desviados: FINNIS (2011j), pp. 429-430: "...what is central in a range of types or instances, o focal in a range of meanings, is relative to viewpoint and purposes, including theoretical purposes".

29 FINNIS (2011j), p. 426: "...there can be non-evaluative, neutral, value-free descriptions of evaluations, i.e. of the value judgments that particular people or peoples make (and give effect to in normative institutions of many kinds)". Véase igualmente, FINNIS (2011g), pp. 232-233: "So description can and, for many purposes, should be value-free even when it describes the values and consequent actions of persons"; pero "One's aspiration as a theorist about law and legal systems is to identify and affirm general and warranted propositions about a human practice or institution thoroughly shaped by thought". Esto implica que se puede, si se quiere, hacer una distinción entre un tratamiento del derecho que es, tratamiento valorativamente neutral y meramente descriptivo, y uno del derecho que debe ser, el cual será propio de una teoría de la ley natural, tal como pretendía Austin. Pero el primero nunca podrá ser general, sino una mera descripción de algún sistema jurídico particular. Véase sobre esto, FinNis (2000), p. 1604.
} 
realidad social ${ }^{30}$. En efecto: una descripción de este tipo sólo podrá explicar qué es el derecho para tal o cual persona, pero no qué es el derecho en general. Así como un análisis del concepto de derecho vehiculado por el término "derecho" no puede dar origen a nada más que una lexicografía, asimismo una teoría realizada con la metodología que Hart propone no puede dar lugar a nada más que a una sociología de tal o cual sistema jurídico. "Y la teoría del derecho, como las otras ciencias sociales, aspira a ser más que una conjunción de lexicografía con historia local, o incluso que una yuxtaposición de todas las lexicografías unidas con todas las historias locales" ${ }^{\prime \prime 31}$. Como dirá Jeremy Waldron, siguiendo a Finnis, el teórico que asume tal posición, está haciendo filosofía del derecho oratio obliqua: "al momento de captar, comprender y reportar lo que es su punto de vista [el de otros] (sin aceptarlo necesariamente), el teórico del derecho hartiano no estaría haciendo filosofía del derecho en su propia voz. Más bien, estaría haciendo algo así como historia o sociología de la filosofía del derecho. Los verdaderos filósofos del derecho son aquellos cuyo punto de vista está tratando de captar"32.

Por ende, el teórico general del derecho debe responder él mismo la pregunta con la que comienza necesariamente toda teoría general del derecho, esto es, la pregunta por su fin. "La investigación acerca del derecho comienza de modo lo suficientemente modesto como: ipor qué tener el tipo de cosa o cosas que son llamadas el derecho y el sistema jurídico, instituciones jurídicas, y procesos y acuerdos que llamamos el derecho de nuestro tiempo y lugar? ‘ Por qué tenerlo?' Es, por supuesto, elíptico para '¿por qué debemos tenerlo, si es que debemos tenerlo?" ${ }^{\prime 33}$. La pregunta inicial del teórico general del derecho es, entonces, un "tipo de pregunta radicalmente práctica" ${ }^{34}$.

De hecho, incluso cuando un teórico descriptivo que quiere hacer una teoría general del derecho de modo pretendidamente neutral desarrolla su teoría, necesariamente-aunque de modo subrepticio- tendrá que recurrir a valoraciones propias respecto de para qué sirve el derecho. Así, por ejemplo, "un sistema jurídico [para Hart] es un sistema en el cual han surgido reglas 'secundarias'

\footnotetext{
$30 \mathrm{Y}$, en estricto rigor, no podrá dar lugar a teoría alguna, desde que "Social theory or science deals with the general (while using the device of central cases and focal meanings to avoid overlooking or neglecting the particulars)": FINNIS (2011j), p. 426.

31 FINNIS (1980), p. 4.

32 WALDRON (2001), p. 425.

33 FinNIS (2011a), pp. 24-25.

34 FINNIS (2011a), p. 25.
} 
para remediar los defectos de un régimen prejurídico que contuviese sólo 'reglas primarias'"135.

Ahora bien: una vez comprendido que el teórico del derecho sólo puede realizar su teoría general intentando responder a la pregunta de por qué es necesario el derecho, se puede ver por qué, para Finnis, la respuesta a dicha pregunta sólo puede ser que debe existir porque es moralmente necesario. En efecto, según se recordará, Hart sostenía que los motivos de aceptación de una regla social o un sistema normativo podían ser diversos, de modo que el teórico del derecho no tenía por qué necesariamente asumir de modo imaginativo la posición de quien cree que es moralmente necesario que exista el derecho.

35 FinNIS (1980), p. 7. Véase, asimismo: "Hart argues, against Kelsen and (in a different way) Bentham and Austin, that rules conferring private power on individuals (for example to make a contract) should not be described as mere fragments of obligation-imposing rules. His argument adduces or describes no fact that Bentham, Austin and Kelsen had failed to describe, other than the truth that there is reason to want and value private powers, a kind of reason different from the reasons to want and respect rules making certain kinds of act or forbearance obligatory. About this truth, Hart was not normatively inert. ... Of course, he begins by saying that, to understand these rules (and their distinctness from obligationimposing rules), we must look at them 'from the point of view of those who exercise them'. But his point of view proves to be simply (or at least primarily) his, yours and mine, not because they are his, yours, or mine, but because it seems true to him, you and me, that there is value in having the rules at stake, reason for having them (which is not in the least incompatible with our also understanding that there might be circumstances where countervailing reasons might give sufficient reason not to have them)": FinNIs (2011a), p. 36. Así, si Hart hubiese sido consecuente con su pretensión de que su teoría es valorativamente neutral y se limita a describir valoraciones de otros, entonces nunca hubiese podido afirmar que el derecho se entiende a partir de los problemas que tiene un sistema normativo prejurídico: FinNIS (2011g), 246: "Hart's method should have restricted him to the observation that people often think they have reasons, that many people think or have thought that a pre-legal set of social rules is defective, think that secondary rules are the remedy, and so forth".

Podemos agregar todavía otro ejemplo: véase, la crítica de Hart a la reducción de toda norma jurídica a directivas para el juez, en HART (1994a), pp. 38-39, como distorsionadora de la función del derecho penal (evitar que existan delitos, no castigarlos), función obviamente afirmada en propia persona.

Como resalta Cristóbal Orrego, hay otras aserciones generales en la teoría hartiana que suponen evaluaciones, v.gr, la tesis de la discrecionalidad de los jueces en los casos no resueltos por el derecho positivo (supone la tesis normativa general de que los jueces deben resolver todos los casos, el principio de inexcusabilidad judicial), o la tesis de que los jueces, en tales casos, recurren a principios jurídicos y morales (supone la tesis general de que ello es lo que deben hacer por ser lo jurídicamente exigido, ya que no puede defenderse como una generalización a partir de lo establecido por sistemas jurídicos particulares). Véase, OrRego (1997), pp. 62-63. También íd, pp. 149-153, sobre la necesidad de las valoraciones en propia persona para la identificación de los diversos tipos de reglas que constituyen el derecho según Hart.

Un caso distinto es, ciertamente, el de la doctrina hartiana del "Derecho Natural de Contenido Mínimo". Su relación con su teoría general del derecho es discutible, y además no es claro hasta qué punto es una teoría sobre un contenido moral necesario del derecho. Sin embargo, ha dado lugar a que algunos intérpretes Ilamen, tal vez exageradamente, "iusnaturalista" a Hart. Véase De PraDA GARCíA (2006), quien además inserta al "iusnaturalista" Hart en la tradición de la Escuela del Derecho Natural Racionalista. Sobre esto, véase también ORREGo (1997), pp. 168-174. 
Sin embargo, Finnis cree que existe un caso central de punto de vista interno, y es precisamente el caso de quien cree que la existencia del derecho es una exigencia moral. Ello, porque sólo una persona así captará la importancia, la significación del derecho para la vida social, porque sólo una persona así pondría un sistema jurídico, o haría los esfuerzos necesarios para ponerlo, ahí donde éste no existiese.

Por una actitud irreflexiva heredada o tradicional, o por el mero deseo de hacer como los demás, se puede ciertamente aceptar una regla jurídica ya puesta y cumplir con ella, pero una persona que acepta y obedece al derecho sólo por tales motivos, no captará su importancia o significación, "porque no tiene la preocupación, que Hart mismo reconoce como fuente explicativa del orden jurídico, por remediar los defectos de un orden social prejurídico"36. Por su parte, quien obedece al sistema jurídico por autointerés "disminuye cualquier preocupación que pueda tener por la función del derecho como una respuesta a problemas sociales reales... diluye su compromiso con el derecho y su compromiso con métodos de pensar jurídicos con dosis de aquel autointerés cuya subordinación a las necesidades sociales es (en la visión de todos) una función esencial del derecho" ${ }^{\prime \prime 3}$.

En cambio, si existe un punto de vista según el cual sea una exigencia de justicia que exista el derecho, como sistema normativo distinto de otros sistemas normativos, entonces tal punto de vista es el caso central del punto de vista jurídico, porque "sólo desde un punto de vista tal es un asunto de importancia primordial que deba surgir el derecho, como algo distinto de otras formas de orden social y, por ello, se vuelva objeto de la descripción del teórico" ${ }^{\prime \prime 3}$. El punto de vista de quien cree que existen razones morales para que exista el

36 FINNIS (1980), p. 14.

37 FinNis (1980), p. 14.

38 FINNIS (1980), p. 15.

Esto es particularmente importante: el punto de vista defendido por Finnis como el que debe adoptar el teórico general del derecho, no es defendido solamente porque pueda explicar por qué las reglas jurídicas son razones para la acción -la normatividad del derecho-, que es lo que afirma Pereira: "Los filósofos analíticos comprenden que la norma funciona, característicamente, como razón para la acción en el razonamiento práctico. Según Finnis, esto implica que, si se quiere reconocer la racionalidad de este razonamiento, no puede negarse que tal funcionamiento obedece a que la norma es razón para la acción. Por tanto, el filósofo analítico, para no reducir arbitrariamente su comprensión del comportamiento, debe admitir que si la norma funciona como razón para la acción es porque tiene algún atractivo racional. Y, a la vez, que tenga atractivo racional se debe a que participa de alguna forma en el bien inteligible. De este modo, Finnis ofrece una comprensión práctica interna, de por qué las normas son razones para la acción. Así, desde la descripción fáctica, externa, del comportamiento como respuesta a razones, llega a la comprensión interna del comportamiento libre como elección racional. Si el comportamiento humano tiene sentido, el hecho de la obediencia a las normas debe responder no a cualquier razón, sino a una suficientemente razonable": Pereira Sáez (2006), pp. 257-258. 
derecho y, consiguientemente, para obedecerlo, es el caso central de punto de vista jurídico.

¿Por qué una persona razonable prácticamente captaría que es una exigencia de justicia que exista el derecho y que, por ende, ahí donde éste no exista, debe ser puesto? Porque una tal persona capta que "hay bienes humanos que sólo pueden ser asegurados a través de las instituciones del derecho humano, y exigencias de razonabilidad práctica que sólo aquellas instituciones pueden satisfacer"39. Y que tales bienes, y el cumplimiento de tales exigencias de razonabilidad práctica, son necesarios para el florecimiento humano. En otras palabras, que el derecho es condición de posibilidad del florecimiento humano, en una sociedad mínimamente compleja ${ }^{40}$. Y lo es no sólo porque posibilita el

Es correcto que Finnis pretende que su teoría puede explicar mejor que las de Hart y Raz el carácter normativo del derecho -que sus elementos sean razón para la acción-, pero su defensa de la adopción del punto de vista del hombre prácticamente razonable no se basa solamente en aquello -Hart y Raz podrían decir que sus propias teorías explican bastante bien qué sea el derecho, dejar claro que para los participantes las reglas jurídicas constituyen razones para la acción, y dejar la tarea de valorar las diversas razones por las cuales los participantes consideran que las reglas jurídicas son razones para la acción a una posterior teoría normativa-. Lo que Finnis pretende es, más bien, que teorías como la de Hart y Raz, por no adoptar el punto de vista del hombre razonable para describir al derecho, no pueden realmente dar cuenta de su surgimiento, que Hart mismo considera que ilumina la descripción del derecho, como sistema normativo diferenciado de otros sistemas normativos. Sólo quien entiende que el derecho es condición de posibilidad del florecimiento humano realmente entiende por qué es necesario -moralmente- que el derecho exista, y exista como distinto de la moraly, consiguientemente, se vuelva objeto de la descripción del teórico.

Sí estamos de acuerdo, con todo, con Pereira Sáez cuando expone que "frente a Hart y Raz, Finnis propone adoptar una perspectiva interna crítica, que permita discernir cuál de las posibles razones del comportamiento tiene mayor fuerza explicativa": PereiRa Sáez (2006), p. 260, pero fuerza explicativa sobre todo respecto de la existencia misma del derecho. "¿Por qué existe el derecho?", dice Finnis, equivale a "¿Por qué debería existir el derecho?".

39 FINNIS (1980), p. 3.

40 Tenemos que añadir "en una sociedad mínimamente compleja", porque Finnis afirma, sorprendentemente, que es posible el florecimiento humano en sociedades sin derecho, pero sólo en sociedades no complejas. Véase (2011h), p. 368: “Indeed, natural law principles, which universally require everyone to refrain from killing the innocent, do not universally require the establishment of a state and, therefore, do not universally require the enacting of a positive (state) law against murder: consider the situation of Eskimos for many centuries". No tenemos claro si esta posición es compatible con el resto de su filosofía. Podría decirse que algo se había adelantado en Natural Law and Natural Rights: "There are, in the final analysis, only two ways of making a choice between alternative ways of co-ordinating action to the common purpose or common good of any group. There must be either unanimity, or authority. There are no other possibilities", FINNIS (1980), p. 232, pero "Unanimity is far beyond the bounds of practical possibility in the political community", íd, p. 233, énfasis añadido. Por ende, podría vivirse sin autoridad en una sociedad no política. Lo que no dice ahí es que se pueda florecer en dicha sociedad, y dicha afirmación, tácitamente afirmada en el texto citado inicialmente, parece contraria a todo el sentido de su filosofía, incluyendo su teoría del florecimiento humano como participación en el mayor grado posible en los bienes humanos básicos y sus derivados. En todo 
florecimiento humano -al posibilitar la coordinación de acciones en favor del bien común-, sino además porque sólo el derecho puede cumplir tal función en una sociedad mínimamente compleja ${ }^{41}$.

Podemos decir así que, mientras para los realistas jurídicos es necesario asumir la perspectiva de "nuestro amigo el hombre malo" para desarrollar una teoría del derecho, para Hart se trata de asumir inicialmente la perspectiva de quien acepta las normas y las usa como criterio para evaluar su conducta y la de los demás, sean cuales sean los motivos por los cuales acepta tales normas. Para Finnis en cambio, sólo se puede hacer una teoría general del derecho si se asume la perspectiva de aquel a quien podemos llamar "nuestro amigo el hombre bueno". Sólo una persona así puede responder la pregunta de por qué es necesario tener derecho, como sistema normativo distinto de la moral ${ }^{42}$.

Pero aun se puede especificar más: dentro de quienes creen que es una exigencia de justicia que exista el derecho en cuanto condición de posibilidad del florecimiento humano, habrá quienes tengan creencias más razonables relativas al florecimiento humano. Si se quiere captar por qué es importante y significativo el derecho, en cuanto condición de posibilidad del verdadero florecimiento humano, entonces serán las evaluaciones de tales personas las que servirán de guía para determinar el caso central de derecho. "Así el caso central de punto de vista es, él mismo, el punto de vista de aquellos que no sólo apelan a la razonabilidad práctica, sino que también son prácticamente razonables, es decir: consistentes; atentos a todos los aspectos de la oportunidad y florecimiento humano, y conscientes de su conmensurabilidad limitada, preocupados por remediar deficiencias y errores, y conscientes de las raíces de los mismos en los variados aspectos de la personalidad humana y en las condiciones económicas y materiales de otro tipo de la interacción social"43.

caso, queda claro que, en sociedades con un mínimo de complejidad, el derecho sí es condición de posibilidad del florecimiento humano.

41 Sobre esto, véase Finnis (2011b), donde defiende la tesis de que sólo el derecho puede otorgar un sistema de soluciones de coordinación estables en una sociedad compleja. De ello concluye que hay una obligación moral genérica prima facie de obedecer al derecho positivo.

42 De ahí que para Finnis sea absurdo el lugar común repetido por algunos positivistas de que el iusnaturalista debiese considerar superfluo el derecho, dado que éste "reproduciría" meras exigencias morales. El derecho no "reproduce" o "copia" la moral: determina reglas morales infradeterminadas, les otorga carácter autoritativo, permite coordinar las acciones de un modo imposible por la moral, al estar compuesto por reglas públicas y compartidas, y se impone coactivamente a los recalcitrantes, y todo ello porque así lo exige el bien común. Véase, FinNis (2000), p. 1608. El ejemplo clásico de tal crítica positivista en KeLSEN (1949), pp. 485-486.

43 FINNIS (1980), p. 15.

Se puede captar la importancia de realizar esta diferenciación ulterior y, consiguientemente, destacar y adoptar, dentro de los puntos de vista de quienes creen que hay razones morales para que exista el 
¿Qué diría una persona moralmente buena o, lo que es lo mismo, prácticamente razonable que es el derecho, si es que fuese un teórico del derecho desarrollando una teoría general del mismo? La respuesta es la definición que da Finnis de derecho -nuevamente, la definición de derecho en su caso central, y que ha sido construida y defendida en todas las páginas de Natural Law and Natural Rights que preceden a su enunciación, mediante la determinación de las características que debe tener un sistema de reglas coactivo que haya de proteger el bien común-: "reglas hechas, de acuerdo a reglas jurídicas regulativas, por una autoridad determinada y efectiva (ella misma identificada y, comúnmente, constituida como institución por reglas jurídicas) para una 'comunidad completa', y apoyadas por sanciones de acuerdo con las estipulaciones guiadas por reglas de instituciones adjudicativas, estando este conjunto de reglas e instituciones dirigida a resolver razonablemente cualquiera de los problemas de coordinación de la comunidad (y a ratificar, tolerar, regular o superar (override) soluciones de coordinación de cualesquiera otras instituciones o fuentes de normas) para el bien común de tal comunidad, de acuerdo a un modo y forma ellos mismos adaptados a tal bien común por caracteres de especificidad, minimización de la arbitrariedad y mantención de una situación de reciprocidad entre los sujetos del derecho, tanto entre ellos mismos como en sus relaciones con las autoridades legítimas" ${ }^{\prime 4}$. El bien común de la comunidad completa es,

derecho, el de quien es prácticamente razonable y, consiguientemente, no el de quienes no lo son y sólo apelan -aun cuando sea de buena fe-, a la razonabilidad práctica. Y es que distintas concepciones del bien humano dan lugar a distintos conceptos de derecho, entre quienes creen que hay razones morales para que exista el derecho, de modo que no es irrelevante si se adopta tal o cual perspectiva. Un marxista o un nazi, por ejemplo, que crean que hay razones morales para la existencia del derecho [dejando de lado la cuestión de si un marxista puede creer que hay razones morales para que haya derecho], ¿podría dar una definición del mismo como la que da Finnis, que incluye referencia explícita a los requerimientos del Imperio del Derecho?

[Por supuesto que un marxista podría pretender que su propia definición, que no incluye los elementos del Imperio del Derecho, es mejor que la de Finnis, pero es dudoso cuánto poder explicativo tenga una definición marxista de derecho respecto de los modernos sistemas jurídicos].

Por otro lado, se comprende también que esta exigencia, la de adoptar el punto de vista del hombre razonable, por sí sola es incompatible con la pretensión hartiana de que el teórico, para escoger el caso central de derecho, debe describir las valoraciones que subyacen a la aceptación hecha por otros, sin necesariamente compartirla (una descripción "desvinculada"). Es obvio que no se puede describir una valoración de quien se considera una persona razonable prácticamente, o moralmente buena, sin necesariamente compartir dicha valoración. Como dice Bix, "for the theorist to be making judgments about which perspective is the most practically reasonable (more or less the equivalent of saying which perspective gets the moral-ethical question right) is for the theorist to be making moral judgments": Bix (1999), p. 186. Véase igualmente, Bıx (2000), pp. 1619-1620. Por eso, piensa Finnis, el teórico del derecho realmente hace filosofía del derecho en propia persona.

44 FinnIs (1980), pp. 276-277. Nótese que Finnis define al derecho casi al final de Natural Law and Natural Rights, en el décimo capítulo, titulado "Law". Antes ha tratado de la necesidad de cada uno de los elementos de la definición para asegurar el bien común. Así, en el capítulo VI trata sobre el 
por su parte, "el conjunto completo de condiciones materiales y de otro tipo que tiendan a favorecer la realización, por cada individuo en la comunidad, de su propio desarrollo personal" ${ }^{\prime 4}$.

¿Y no se requiere un previo conocimiento descriptivo de la realidad sobre la cual se quiere hacer una teoría general normativa? Por cierto que sí, pero tal conocimiento no es el provisto por una pretendida teoría general descriptiva valorativamente neutral, sino que basta con el conocimiento preteorético común que todos tenemos del derecho para iniciar la teoría general preguntándonos por qué tener derecho: "la realidad primaria del derecho se encuentra... en su pretensión [de influir], ella misma una exigencia moral, sobre mi deliberación acerca de qué decidir -esto es, qué juzgar acerca de las opciones que me son disponibles, y qué decidir y hacer una vez que haya emitido mi juicio-. Este modo de existencia de nuestro derecho positivo -como una pretensión moralmente legítima e imperativa, aun cuando imperativa condicionalmente y sólo de modo superable, sobre mi acción cuando estoy pensando qué hacer como un ciudadano normal (niño o adulto), un juez, un oficial de policía, un inspector tributario, y albacea, y así sucesivamente -es la realidad primaria del derecho. Es primaria porque la fuerza racional de esta pretensión es completamente inteligible incluso antes de que uno conozca cualquier cosa acerca del contenido del derecho y, ciertamente, antes de que se le haya enseñado algo a uno acerca del derecho en general o 'el concepto de derecho'"146. De modo preteorético ya captamos que la pretensión de aquella realidad a la que llamamos "derecho" de afectar racionalmente nuestra acción se encuentra justificada porque, de modo confuso y preteorético, captamos que el derecho es condición de posibilidad del logro de ciertos bienes humanos. Ese es el genuino punto de partida de una teoría general del derecho, que por ser general tendrá que tener necesariamente

bien común mismo, en el VII sobre la justicia, el VIII sobre los derechos (subjetivos), y el IX, sobre la autoridad. Su tratamiento del derecho es posterior a la elucidación de qué sea el bien común, por qué es necesaria la autoridad para alcanzarlo, cuáles son las exigencias de la justicia (entre ellas, la existencia del derecho positivo mismo), etc..., de modo que cada uno de los elementos de su extenso concepto de derecho se encuentra justificado por el tratamiento previo. Dicho tratamiento y justificación particular de cada elemento no es objeto de este trabajo, sino sólo la metodología seguida por Finnis. Ciertamente, frente al minimalismo de ciertas definiciones - derecho es "la unión de reglas primarias y secundarias", "las profecías de lo que harán los jueces"-, la de Finnis parece extremadamente maximalista. Cfr., lo que dice Soper: "No one will be able to put Finnis's 'definition' of law in slogan form: the definition is contained in a sentence of more than 140 words that runs a full paragraph and refers to almost every related aspect of law that Finnis has discussed in preceding chapter": SOPER (1983), p. 1184. Pero recuérdese que esta definición se refiere al exigente caso central propuesto por Finnis, de ahí su carácter extenso. La extensión de la definición es consecuencia del carácter exigente del caso central de derecho identificado.

45 FINNIS (1980), p. 154.

46 FINNIS (2011a), p. 29. 
pretensiones normativas, en cuanto pretenderá responder la pregunta "¿por qué tener derecho?", y cuyos conceptos podrán ser utilizados en una empresa descriptiva aplicándose también de modo legítimo a los casos no centrales.

\section{Concepto de Derecho y criterios de identificación de normas}

Conviene aquí responder una objeción que se puede adivinar. ¿No hay diversas concepciones acerca de lo que sirve al bien común, o de cuándo se satisfacen las exigencias del Imperio del Derecho, o de cualquiera de los elementos de carácter moral que Finnis incluye en su definición? ¿No llevaría, el aceptar la definición de Finnis, a una imposibilidad de ponernos de acuerdo respecto de si tal o cual pretendida ley lo es realmente, es un caso central, o es un caso desviado, que tal vez no merezca obediencia? ¿No impide esto identificar normas comunes por las cuales guiar nuestro comportamiento? $Y$ esa imposibilidad, ¿no afectaría ella misma al bien común?

La respuesta es: no. Por la simple razón de que la definición dada por Finnis no pretende ser un criterio de identificación de normas. Es una definición que intenta explicar una práctica social con la cual ya estamos todos familiarizados, sirve para entender qué sea el derecho. No pretende ser un test que debamos seguir en nuestra práctica cotidiana para identificar normas ${ }^{47}$. Es obvio que todos lo hacemos siguiendo lo que Hart llamaba "regla de reconocimiento", la cual pocas veces incluye criterios morales sustantivos ${ }^{48}$.

Así, tras haber analizado las reglas jurídicas en términos razianos, como razones protegidas para la acción, Finnis expresa que "he enfatizado el modo como la empresa de ejercer la autoridad por medio del derecho procede por la posición de un sistema de reglas que derivan su autoridad no de la bondad

\footnotetext{
47 FinNis (2011i), p. 289: "Positivist and natural law theories in jurisprudence are not, and do not even look like, theories about the law of any particular community (in the sense of offering to identify propositions of law which are true for that legal system), or about the criteria for identifying the law which are used by the lawyers and judges of any particular community".

48 Se puede hacer una analogía con las discusiones relativas a qué sea la verdad. Como se sabe, hay mucha discusión al respecto. Si se objeta a quien pretende que la verdad sea correspondencia entre una oración/enunciado/proposición/pensamiento con la realidad/hechos/estados de cosas, que con tal definición no podemos identificar qué portadores de verdad sean verdaderos (¿cómo vemos qué portadores de verdad se adecuan a la realidad?), la respuesta obvia es que dicha definición no pretende ser un criterio de identificación de portadores de verdad verdaderos, y que tal criterio es parte de una teoría de la justificación. Pero que identifiquemos a los portadores de verdad usando otros criterios, por ejemplo, su coherencia con otras proposiciones tenidas por verdaderas, no significa que no se puede defender que la verdad sea correspondencia.

Por otro lado, decimos, además, que la regla de reconocimiento pocas veces incluye referencia a criterios morales sustantivos, porque Finnis acepta la posibilidad de que los incluya (en esto, su posición coincide con la del positivismo jurídico incluyente).
} 
(appropiateness) de su contenido, sino del hecho de su estipulación de acuerdo a reglas de estipulación" ${ }^{49}$. Esta "separación" -parcial- del sistema jurídico del "flujo irrestricto del razonamiento práctico respecto de qué sea justo y necesario para el bien común" son "respuestas prácticamente razonables para la necesidad de seguridad y predictibilidad, una necesidad que es, de hecho, materia de justicia y derecho humano" ${ }^{\prime 50}$.

Lejos de ser una "claudicación" frente al positivismo ${ }^{51}$, la concepción del derecho como autoritativo se basa en la tesis de que la coordinación de acciones humanas y la cooperación entre los seres humanos, necesarias para el florecimiento humano, no serían posible si no existiesen reglas comunes compartidas, públicas, definitivas respecto a qué ha de hacerse u omitirse, exigiendo obediencia aun en ausencia de razones entendidas, vale decir, pretendiendo tener carácter autoritativo ${ }^{52}$. El carácter autoritativo del derecho es, él mismo, una exigencia del bien común, y por ello es moralmente obligatorio que el razonamiento jurídico sea parcialmente, pero lo más posible, aislado del razonamiento práctico general ${ }^{53}$. De ahí que Finnis diga que "el razonamiento jurídico es (al menos en gran parte) razonamiento técnico -no razonamiento moral" ${ }^{\prime 54}$. Como

\footnotetext{
49 FinNIS (1980), p. 355.

50 FinNIS (1980), p. 356. Véase también lo que dice en "The Truth in Legal Positivism": "...constitutionmakers have a moral responsibility to establish sources of law which can be identified without resort to moral argument, and judges and other subjects have a moral responsibility to defer (within limits) to such sources" Finnis (2011e), p. 185. Lo cual, nuevamente, no significa que se pueda entender bien qué sea el derecho sin comprender su relación con la moral: "Though human law is artefact and artifice, and not a conclusion from moral premises, both its positing and the recognition of its positivity (by judges, professionals, citizens, and thence by descriptive and critical scholars) cannot be understood without reference to moral principles that ground and confirm its authority or challenge its pretention": FinNIS (2011e), p. 186.
}

51 "Once one concedes, as Finnis does, that the existence and content of law can be identified without recourse to moral argument, and that 'human law is artefact and artifice; and not a conclusion from moral premises,' (p. 205) the Thomistic apparatus he tries to resuscitate is largely irrelevant to the truth of legal positivism": GreEN (2003), p. 3.

52 Como dice Pereira Sáez, "En el caso del derecho, según Finnis, la condición de razón excluyente radica en la bondad de su forma": Pereira SÁez (2008), p. 6.

53 Véase, Pereira SÁez (2008), p. 176: "Así la tesis principal de su filosofía jurídica establece que, entre los posibles criterios de comportamiento que orientan al bien común de la comunidad política, sólo el derecho es aceptado como autoritativo porque sólo el derecho proporciona razones suficientes, morales, para obedecerlo, razones que dan sentido a su obediencia también en caso de desacuerdo con su contenido.

Esta tesis aparece en su obra como compatible con la tesis de las fuentes sociales, según la cual el derecho se identifica por su origen y su condición jurídica es independiente de toda valoración sobre su contenido".

54 FINNIS (1992), p. 142. 
expresa Maris Köpcke Tinturé, hay en Finnis una defensa de "la necesidad moral de que el pensamiento jurídico se aísle del pensamiento moral" ${ }^{\prime 55}$, y de que el derecho tenga cuatro características, que la moral no tiene, sin las cuales no podría permitir la cooperación humana, lo cual es un objetivo moralmente necesario. Estas características son: positividad, carácter determinado -el derecho determina principios morales indeterminados-, facilidad de identificación -de ahí la necesidad de que la regla de reconocimiento haga referencia sobre todo a criterios formales-, y carácter conclusivo -no tolera excepciones a lo que prescribe que él mismo no haya tomado en consideración, vale decir, que "las exigencias jurídicas son siempre no-derrotables desde el punto de vista del derecho (in contemplation of law) ${ }^{\prime \prime 56}$.

Y, por último, entender que el carácter autoritativo del derecho deriva, precisamente, de su capacidad de posibilitar el bien común, permite explicar aquella característica del derecho que tanto cuesta a los positivistas explicar: su normatividad. Y es que, para Finnis, explicar la normatividad del derecho desde una perspectiva positivista es imposible, porque cualquier intento en tal sentido terminará deduciendo un deber ser de un ser -iprecisamente aquello que ciertos positivistas tienden a enrostrar al iusnaturalismo tradicional!-. Si el derecho es mero hecho, aunque sea un hecho social, entonces no puede dar razones para la acción, porque los hechos por sí solos no son normativos ${ }^{57}$.

\footnotetext{
55 KöPCKe Tinturé (2013), p. 379.
}

56 KöPCKE Tinturé (2013), p. 388. Desde el punto de vista del derecho, porque desde el punto de vista del individuo, pueden ser derrotadas por el razonamiento moral. Por ello, "legal obligation in the moral sense (the 'moral obligation to obey the law') is 'variable', i.e., defeasible in force: there is a standing possibility that steps $A$ and $B$ lose some or all of their purchase in the face of some kind of injustice that overrides the very good reasons for having a system of positive law" (íd, 392). Pero el derecho, a su vez, no podrá aceptar tal comportamiento del individuo.

Sobre estas cuatro características necesarias del sistema jurídico atendido el fin práctico del mismo, véase KöPCKE TINTURÉ (2013), pp. 384-389, un artículo muy esclarecedor sobre el tema de la positividad del derecho y su carácter moralmente necesario, así como el carácter "aislado" del pensamiento jurídico respecto del razonamiento práctico general en John Finnis.

57 "These latter-day thinkers, moreover, all failed to grasp steadily that 'ought' cannot be derived from 'is'. As the débacle of Kelsen's late jurisprudence so powerfully illustrates, the fact of positivity, without the support of some prior normative principle, can yield neither a rational claim on the delibarations of judge or citizen nor a ground for construing the law as a system: FinNIs (2011e), p. 186. Precisamente Kelsen, con su insistencia en la separación entre ser y deber ser, su consiguiente negativa a explicar la normatividad del derecho en términos fácticos, y su negativa a hacer depender la normatividad del derecho de la moral, terminó postulando su famosa "Grundnorm", de la que al final de su vida diría que es una ficción. Del mismo modo, Finnis (2000), p. 1608: "As the fifty-five years of Kelsen's jurisprudence abundantly illustrate, positivism's efforts to explain the law's authority are doomed to fail". Finnis acepta plenamente la Ilamada "ley de Hume", y en su teoría moral no pretende deducir normas morales de meras descripciones, ni siquiera de descripciones de la naturaleza humana, sino de la captación racional de ciertos ítems como buenos para el hombre. Véase FinNis (1980), pp. 23-99. 
En breve: Finnis no niega el carácter autoritativo del derecho -su pretensión de ser obedecido aun en ausencia de razones entendidas-, su carácter positivo, su carácter decisivo -que lo llevan incluso a imponerse por sobre las exigencias de la moral de los individuos-, su carácter de estar respaldado por sanciones, características todas ellas tan recalcadas por los autores positivistas. Para Finnis, tales son características necesarias del derecho si es que éste ha de cumplir la función social que debe cumplir, vale decir, posibilitar la cooperación humana en vistas al bien común. Finnis no niega "el origen social" del derecho: lo entiende y explica a partir del fin práctico del mismo. Brian Bix, comentando la disputa entre positivismo y iusnaturalismo contemporáneo, expone que "bien puede ser que la doble naturaleza del derecho -como una institución social y como una práctica que da razones [para la acción]- haga imposible capturar la naturaleza del derecho completamente a través de una única aproximación, con una aproximación más 'neutral' (como el positivismo jurídico) necesaria para entender su faz institucional, y una aproximación más evaluativa (como la teoría de la ley natural) necesaria para entender su faz dadora de razones) ${ }^{\prime \prime 58}$. Es claro que la pretensión de Finnis es que el carácter institucional sólo se puede entender a partir del carácter de moralmente necesario del derecho ${ }^{59}$. Pero todo ello debe ser objeto de un estudio por separado.

Sin embargo, deja claro que, desde el punto de vista ontológico, la naturaleza humana funda el bien humano: véase, FinNIS (2011j), p. 416.

Más aún: Finnis cree que la llamada "ley de Hume" -la imposibilidad de deducir exigencias normativas de meras descripciones-, lejos de ser incompatible con el tomismo, fue enunciada por primera vez por santo Tomás de Aquino y, no por Hume, quien, además, no la habría enunciado en el conocido pasaje del Treatise en el cual se le atribuye dicho descubrimiento, sino que habría estado tratando un tema diverso del de la relación lógica entre tipos de enunciados: el de la capacidad de la percepción de cualidades morales de motivar la acción. Véase, sobre su interpretación de Hume, FinNis (1980), p. 36-48. Su interpretación de la afirmación tomista de dicho principio en FinNIS (1998), pp. 79-94. Finnis aquí es fuertemente deudor de la interpretación de santo Tomás desarrollada por Germain Grisez, particularmente en su artículo seminal Grisez (1965).

58 Bix (2005), p. 89.

59 Es conveniente dejar mencionado que, igualmente, hay otras tesis tradicionalmente asociadas con el positivismo que Finnis sostiene y cree enteramente compatibles con su teoría del derecho iusnaturalista: ante todo, que el sistema jurídico no otorga siempre una única respuesta correcta (véase FinNis [2011i], especialmente 290-295), o que una ley injusta tiene validez jurídica, vale decir, aunque sea un caso deficiente de ley, y sea jurídicamente deficiente, vista desde el punto de vista intrasistémico que asume un operador jurídico, es válida (lo cual no responde, en todo caso, la pregunta de si debe ser aplicada, incluso por un juez, consideradas todas las cosas); véase FinNIs (1980), pp. 364-365.

Todo ello ha hecho que sea criticado por otros autores insertos en la tradición iusnaturalista tomista, quienes creen que una teoría iusnaturalista no puede aceptar tales tesis. Véase, por ejemplo, VIGO (2013). 


\section{Conclusión}

Las reflexiones metodológicas de Finnis no sólo son originales, sino que han llevado a una profunda discusión sobre el tema en la filosofía jurídica contemporánea, hasta el punto de convencer a varios autores de la tradición positivista de la futilidad de intentar realizar una teoría general del derecho valorativamente neutral, nos referimos, por supuesto, a los autores del Ilamado "positivismo normativo" ${ }^{60}$, como Jeremy Waldron y Neil McCormick, quienes expresamente muestran su acuerdo con Finnis en estos puntos ${ }^{61}$. Un estudio de los supuestos metodológicos de la obra de Finnis abre todavía una serie de interrogantes que sólo queremos dejar planteadas. Un tratamiento como el de Finnis, con su consiguiente definición del derecho cargada moralmente por la inclusión de la noción de bien común ¿compromete a quien la acepte con una teoría moral objetivista, en general, y con una teoría como la finnisiana relativa al bien humano, en particular? Sin querer resolver por ahora el problema, pareciera que intuitivamente se debe responder "sí" a la primera pregunta -lo que nos hace dudar de la coherencia de una empresa como la de un positivismo normativo no comprometido mínimamente con la creencia en el valor objetivo de ciertos bienes (autonomía, paz social, etc.)-, y "no" a la segunda ${ }^{62}$. Pareciera que la teoría metodológica de Finnis fuese lógicamente separable de su particular teoría de los bienes humanos básicos, aunque no pareciera serlo de la idea de una moral objetiva de bienes en general.

\section{BiBLIOGRAFÍA CITADA}

AleXY, Robert (2011): Begriff und Geltung des Rechts ( $3^{\mathrm{a}}$ ed.) (Freiburg y München: Verlag Karl-Alber).

De Aquino, Tomás (1485): Summa Theologiae. Se ocupa la edición crítica online disponible en www.corpusthomisticum.org.

Austin, John (1998) [1832]: The Province of Jurisprudence Determined (Indianapolis: Hackett). Reimpresión de íd. (1954): The Province of Jurisprudence Determined, (London: Weidenfeld \& Nicholson).

\footnotetext{
60 Véase, sobre todo, WaLdron (1996), (2000), y (2001); y MACCormick (1985) y (1992).

61 Véase WALDRON (2001), p. 412, n. 7. Los autores del positivismo normativo consideran que su diferencia más importante con una teoría como la de FinNIs consiste en su rechazo a asumir un compromiso con una teoría metaética "fuerte" como la de Finnis: véase WALDRON (2001), p. 418. Del mismo modo, MacCormick, quien acepta ciertas premisas metodológicas de Finnis en teoría del derecho, expone que "Finnis's own account of the basic goods works from what still seems to me an unacceptable version of meta-ethical cognitivism": МАССоRміск (1992), p. 128.

62 Es lo que piensa Murphy: "So one could affirm a natural law jurisprudence or a natural law political philosophy while rejecting a natural law account of practical rationality": MURPHY (2006), p. 4.
} 
Bıx, Brian (1999): "H.L.A. Hart and the Hermeneutic Turn in Legal Theory", en: SMU Law Review (52), pp. 167-200.

Bix, Brian (2000): "On the Dividing Line Between Natural Law Theory and Legal Positivism", en: Notre Dame Law Review (75), pp. 1613-1624.

Bix, Brian (2005): "Some Reflections on Methodology in Jurisprudence", en Cáceres, Enrique, Flores, Imer, Saldaña, Javier y Villanueva, Enrique (eds.), Problemas contemporáneos de la filosofía del derecho, (México, Unam), pp. 67-96.

BIX, Brian (2009): Jurisprudence, Theory and Context. (Durham, Carolina Academic Press).

De Prada García, Aurelio (2006): "El iusnaturalismo hartiano: una contribución a su análisis", en: Ramos Pascua, José y Rodilla González, Miguel Ángel (eds.), El positivismo jurídico a examen. Estudios en homenaje a José Delgado Pinto (Salamanca, Ediciones Universidad de Salamanca), pp. 217-235.

Dıckson, Julie (2013): "Law and Its Theory: a Question of Priorities", en: Keown y George (2013), pp. 361-378.

EHRENBERG, Kenneth (2009): "Defending the possibility of a Neutral Functional Theory of Law", en: Oxford Journal of Legal Studies (29, 1), pp. 91-113.

ENDicotr, Timothy (2013): "The Irony of Law", en: Keown y George (2013), pp. 327-345.

ETCHEVERRY, Juan (2013): Ley, moral y razón. Estudios sobre el pensamiento de John M. Finnis a propósito de la segunda edición de Ley natural y derechos naturales. (México D.F., Unam).

FINNIS, John (1980): Natural Law and Natural Rights (New York, Oxford University Press).

FINNIS, John (1992): "Natural Law and Legal Reasoning", en: George, Robert P. (ed.) Natural Law Theory. Contemporary Essays, (Oxford, Clarendon Press), pp. 134-156.

FINNIS, John (1998): Aquinas (New York, Oxford University Press).

FinNIS, John (2000): "On the Incoherence of Legal Positivism", en: Notre Dame Law Review (Vol. 75), pp. 1597-1612.

FINNIS, John (2011a) [2003]: "Describing Law Normatively", en: Collected Essays: Volume IV. Philosophy of Law (New York, Oxford University Press), pp. 23-45.

FINNIS, John (2011b) [1989]: "Law as Coordination", en: Collected Essays: Volume

IV. Philosophy of Law (New York, Oxford University Press), pp. 66-73.

FINNIS, John (2011c) [1987]: "Positivism and Authority", en: Collected Essays: Volume IV. Philosophy of Law (New York, Oxford University Press)", pp. 74-87. 
FINNIS, John (2011d) [2005]: "Legal Philosophy: Roots and Recent Themes", en: Collected Essays: Volume IV. Philosophy of Law (New York, Oxford University Press)", pp. 157-173.

Finnis, John (2011e) [1996]: "The Truth in Legal Positivism", en: Collected Essays: Volume IV. Philosophy of Law (New York, Oxford University Press)", pp. 174-188.

FINNIS, John (2011f) [1985]: "Weber, Objectivity, and Legal-Rational Authority", en: Collected Essays: Volume IV. Philosophy of Law (New York, Oxford University Press)", pp. 211-229.

FINNIS, John (2011g) [2007]: "On Hart's Way: Law as a Reason and as Fact", en Collected Essays: Volume IV. Philosophy of Law (New York, Oxford University Press)", pp. 230-256.

FinNIS, John (2011h) [1990]: "Practical Reasoning in Law: Some Clarifications", en: Collected Essays: Volume IV. Philosophy of Law (New York, Oxford University Press)", pp. 353-374.

FINNIS, John (2011i) [1987]: "Reason and Authority in Law's Empire", en: Collected Essays: Volume IV. Philosophy of Law (New York, Oxford University Press)", pp. 281-297.

FINNIS, John (2011j): "Postscript", en íd, Natural Law and Natural Rights, segunda edición (New York, Oxford University Press), pp. 414-479.

FINNIS, John (2013): "Reflections and Responses", en: Keown y George (2013), pp. 459- 515.

Frank, Jerome (2009) [1930]: Law \& the Modern Mind (New Brunswick, Transaction Publishers).

FulLeR, Lon (1969): The Morality of Law (New Haven and London, Yale University Press).

García-Huidobro, Joaquín (1991): "Utilidad epistemológica de una teoría iusnaturalista", en: Revista Chilena de Derecho (Vol. 18, No 3), pp. 405-410.

Green, Leslie. "Legal Positivism." The Stanford Encyclopedia of Philosophy (Fall 2009 Edition), Edward N. Zalta (ed.), URL $=<$ http://plato.stanford.edu/archives/fall2009/entries/legal-positivism/>. Consultado el 4 de febrero de 2016.

GrISEZ, Germain (1965), "The First Principle of Practical Reason: A Commentary on the Summa Theologiae, 1-2, Question 94, Article 2", en: Natural Law Forum (10), pp. 168-201.

HART, Herbert (1958): "Positivism and the Separation of Law and Morals", en: Harvard Law Review (71, № 4), pp. 593-629.

HART, Herbert (1963): Law, Liberty and Morality (Stanford, Stanford University Press). 
HART, Herbert (1983): Essays in Jurisprudence and Philosophy (New York, Oxford University Press).

HART, Herbert (1994a) [1960] The Concept of Law. $2^{a}$ edición. (New York, Oxford University Press).

HART, Herbert (1994b): "Postscript", editado por Penelope Bulloch y Joseph Raz en íd 1994a, pp. 238-276.

Hocevar González, Mayda (2006): "Los casos central y periféricos y el punto de vista moral del punto de vista interno en la teoría del derecho de John Finnis", en: J.A. Ramos Pascua y M.A. Rodilla González (eds.), El positivismo jurídico a examen. Estudios en homenaje a José Delgado Pinto (Salamanca: Ediciones Universidad de Salamanca), pp. 197-215.

Holmes, Oliver Wendell (1897): "The Path of the Law", en: Harvard Law Review (10, No 8), pp. 457-78.

Holmes, Oliver Wendell (1918): "Natural Law", en: Harvard Law Review (32, $\mathrm{N}^{\circ}$ 1) pp. 40-4.

KelseN, Hans (1949): "The Natural Law Doctrine before the Tribunal of Science", en: The Western Political Quarterly, 2, № 4, pp. 481-513.

KeLSEN, Hans (2007) [1945]: General Theory of Law and State (The Lawbook Exchange, New Jersey), reimp. de íd, (Harvard University Press, Cambridge).

Keown, John, y George, Robert P. (eds.) (2013): Morality, and Law. The Philosophy of John Finnis (Oxford, Oxford University Press). Kindle Edition.

KÖPCKE TINTURÉ, Maris 2013, "Finnis on Legal and Moral Obligation", en: Keown y George (2013), pp. 379-395.

Legarre, Santiago (1999): "El concepto de derecho en John Finnis", en: Persona y Derecho ( $\left.\mathrm{N}^{\circ} 40\right)$, pp. 65-87.

Leiter, Brian (1996): "Heidegger and the Theory of Adjudication", en: The Yale Law Journal (106, № 2), pp. 253-82.

Leiter, Brian (1999): "Legal Realism", en: A Companion to Philosophy of Law and Legal Theory, ed. Dennis Patterson (Oxford, Blackwell), pp. 261-279.

Leiter, Brian (2001): "Legal Realism and Legal Positivism Reconsidered", en: Ethics (111, № 2), pp. 278-301.

MacCormick, Neil (1985): "A Moralistic Case for A-Moralistic Law", en: Valparaiso University Law Review (20, No 1), pp. 1-41.

MacCormick, Neil (1992): "Natural Law and the Separation of Law and Morals", en: George, Robert (ed.) Natural Law Theory. Contemporary Essays (Oxford, Clarendon Press), pp. 105-133.

Marmor, Andrei (2011): Philosophy of Law (Princeton, Princeton University Press). 
MOORE, Michael S. (1989): "Torture and the Balance of Evils", en: Israel Law Review (23, No 2-3), pp. 280-344.

MOORE, Michael S. (1992): "Law as a Functional Kind", en: George, Robert(ed.), Natural Law Theories, (Oxford, Oxford University Press).

Moore, Michael S. (1996): "Good without God", en: George, Robert (ed.) Natural Law, Liberalism and Morality, (Oxford, Oxford University Press), pp. 221-270.

Murphy, Mark (2006): Natural Law in Jurisprudence and Politics (New York, Cambridge University Press).

Murphy, Mark (2007): Philosophy of Law. The Fundamentals (Oxford: Blackwell). Orrego Sánchez, Cristóbal (1997): H.L.A. Hart. Abogado del Positivismo Jurídico (Pamplona: Eunsa).

Pereira Sáez, Carolina (2006), "El punto de vista interno en la filosofía del derecho de John Finnis", en Legarre, Santiago, Miranda, Alejandro y Orrego, Cristóbal (eds.), La lucha por el derecho natural. Actas de las Jornadas en Homenaje a John Finnis. A 25 años de la publicación de Natural Law and Natural Rights (Santiago, Universidad de los Andes, Cuadernos de Extensión Jurídica), pp. 249-263.

Pereira SÁez, Carolina (2008) La autoridad del derecho. Un diálogo con John M. Finnis (Granada: Comares).

RusselL, J.S. (2000): "Trial by Slogan: Natural Law and Lex Iniusta Non Est Lex", en: Law and Philosophy (19, $\mathrm{N}^{\circ} 4$ ), pp. 433-449.

Simmonds, N.E. (2013): "Value, Practice and Idea", en: Keown y George (2013), pp. 311-326.

VIGO, Rodolfo Luis (2013): "Consideraciones sobre la visión de John Finnis acerca de la tesis 'la ley injusta no es ley'", en EtcheverRy (2013), pp. 119-140.

Waldron, Jeremy (1996): "Kant's Legal Positivism", en: Harvard Law Review (109, No 7), pp. 1535-66.

Waldron, Jeremy (2000): "Lex Satis lusta", en: Notre Dame Law Review (75, $\mathrm{N}^{\circ}$ 5), pp. 1829-58.

Waldron, Jeremy (2001) "Normative (or Ethical) Positivism", en Hart's Postscript, editado por Jules Coleman (New York, Oxford University Press), pp. 410-433. 